\title{
A Fuzzy ANP Based Grey Relational Approach to Evaluate CRM System in Context of Bangladesh
}

\author{
Abdul Kadar Muhammad Masum* ABM Yasir Arafat MD.Sadek Sultan \\ Shahriar Md. MahirHasnat H. M. AshiqurRahman \\ Department of Computer Science and Engineering, International Islamic University Chittagong, Chittagong, \\ Bangladesh \\ *Corresponding author:akmmasum@yahoo.com
}

\begin{abstract}
This study aims to select a suitable CRM (customer relationship management) system among different possible alternatives for organization's in Bangladesh. Since, evaluating CRM system on the basis of lot of attributes leads us to Multiple-criteria decision analysis (MCDA) problems. In this study, a hybrid MCDA models were used. FuzzyANP (Analytic Network Process) and GRA (Grey Relational Analysis) approaches were adopted to solve the problem. The study explored that the Hubspot CRM was optimal solution in context of Bangladesh. Our research will beneficial to the organizing for better customer support. As far our knowledge goes, this is the first attempt to select CRM softwares in context of Bangladesh.
\end{abstract}

Keywords: Analytic network process; Customer relationship management system; Grey relational analysis; Multiple-criteria decision analysis

DOI: $10.7176 / \mathrm{IKM} / 11-4-06$

Publication date:June $30^{\text {th }} 2021$

\section{Introduction}

Information system (IS)is a strategic weapon for the organizations. Customer relationship management (CRM) is a method to cope with a corporation's cooperation with present and potential clients. It makes use of facts investigation about customers' records with a business enterprise to enhance business courting with clients, explicitly focusing on customers' need. CRM technique is compiling information from a scope of numerous communication channels, consisting of an organization's web site, cellphone, e-mail, live communicate, advertising substances and greater these days, social media. So, the concept of CRM system uses statistics evaluation about clients' records with an agency to improve business relationships with customers, particularly focusing on client relation and ultimately using income increase.

In CRM system, it keeps track of present customer profiles. The organization can generate new techniques to decide which it have targeted to obtain a much wider customer base. But selecting an information system like CRM system is troublesome issue for managers in Bangladesh. Bangladeshi companies are in adverse situation for adopting CRM system as they don't have proper idea about the benefits of CRMS. Improperly selected CRM system might increase prices and time loss. So, considered one of the biggest troubles is to determine the desirable CRM system based their financial strength and existing facilities. Previous research stated that adoption factors of any technology varies demographically because of different culture, infrastructure etc.So, it might not be suitable for Bangladesh selecting a CRM system based on other countries.

Therefore, selection of a suitable CRM system is a major challenge for the business organizations of Bangladesh. It is a strategic decision process for its factor recognition. In this work, we tried to recognize the critical success factors based on extensive literature review and expert opinion for determining a suitable CRM system in the context of Bangladesh. To the best of our knowledge, this type of work had never executed in the context of Bangladesh earlier.

\section{Related Works}

Customer Relationship Management (CRM) system helps to reduce the distance, build and maintain an effective long term relationship with the company's clients. The concept of CRM system doesn't have a proper definition inside both business and academicals networks (Richards \& Jones, 2008). Some authors pointed out that the lacking of expertise regarding CRM system(Francis Arthur Buttle, 2015). Properly, eCRM is identified as an internet-centric way of synchronizing enterprise features, communication channels for maintaining client relationship (Racherla, Hu, \& Marketing, 2008).

With everything taken into account, CRM systems empower organizations to produce client information from numerous and different ways to get far-reaching learning about customer conduct (Khodakarami, Chan, \& Management, 2014). When thinking about technological improvement, organizations are trying to develop a strategic plan by clustering persistent data from various practices (Khodakarami et al., 2014). An ultimate objective of using a CRM system is consistently to trigger the customer service, up-selling and cross-selling (Petrik, October 3, 2017). Moreover maintaining a client-centric business an organization will be fruitful as long as their clients are satisfied, and this is the where CRM systems help the most (Petrik, October 3, 2017). This 
decision brought about the conclusion that "the more companies interact in imposing CRM strategies, principally at the initiation and preservation stage, the better they carry out" (Reinartz, Krafft, \& Hoyer, 2004).

In Bangladesh, CRM system like Capsule, SalesforceIQ, Hubspot CRM, Zoho CRM, Onpipeline CRM, Saleswith, Smart CRM etc. are availed through multinational companies and telecom operators for making their business curve upward by increased revenue and customer satisfaction. Recognizing the rapid sales growth and revenue earning some local companies like Bashundhara Group,Rahimafrooz, Partex, Square, GenIT, Optimal IT 1td. etc. implemented CRMS step by step (HOSSAIN, 2019). From the above CRM system available in Bangladesh, we have shortlisted five CRM system as alternatives i.e. Zoho CRM, Onpipeline, Hubspot CRM, Saleswith, Smart CRM based on same quality system. We have thoroughly examined their features and took expert opinion for the suitable CRM system in context of Bangladesh.

\section{Conceptual Model for CRM adoption}

Information System as like CRM Software can be evaluated based on various frameworks like TOE- Technology Organization environment- framework, TAM - Technology Acceptance Model - theory, DOI - Diffusion of Innovations - theory, etc. Comparing TOE with TAM and DOI, we have seen the TOE framework includes some important factors and it turns out to be better ready to clarify intra-firm advancement adoption. The TOE framework additionally has a strong hypothetical premise, predictable experimental help, and the capability of utilization to IS innovation(Oliveira \& Martins, 2011). So, based on a comprehensive literature survey we sort out every critical success factor studied in previous literatures under3 dimensions of TOE framework.

1) Technological Context - The technological setting depicts both the inward and onward advancements important to the organization, together with those existing within the organization.

- IT Integration System is such a process or phase regarding engineering that concerned with different subsystems or components to make them one large system. IT integration is used to conjugate value to a system through new functionality provided through connection of various system functions.

- Technological readiness gives priority to the level of technical assets in a company's settlement. A CRM initiative is considered expensive and a solid innovation that requires expensive information system infrastructures, technical expertise and integrated information services.

- Client information management is the practice of managing customer data in an association. It is a term that identifies with the more extensive classification of information the executives and it starts with sound record and substance the board rehearses.

- Data Quality and Integration data must be consistent and unambiguous and suitable for its intended uses in decision making, planning and operations. It is commonly publicized that faulty data quality can have a serious influence on the overall performance of a company.

2) Organizational Context - The organizational context is associated to the organization's resources, the size of the company, methodology, hierarchy, managerial structure etc.

- KM Capabilities is the ability of an association to catch, oversee and convey continuous validated client, items and administrations data to improve client reaction.

- Top management support is a very important factor that adopts of a new system in this case CRM. It is supported by senior management of a company (Cruz-Jesus, Pinheiro, \& Oliveira, 2019). This factor is crucial for the pre-adoption and pre-implementation plan of CRM systems.

- Management of customer contact channel presently the contact with customers at organizations are face to face visits but now the scenario is changed because of CRM System (Zahedi, Cheshmberah, \& Tofighi, 2011). Usually, customers contact the organization through different correspondence stations, for example, telephone contact center, the World Wide Web and so forth.

- Perceived Benefits with regards to the study, it denotes how much benefits a firm can achieve by a CRM system. It is the degree to which a new system is perceived as a good solution (Racherla et al., 2008). 
Technological Context

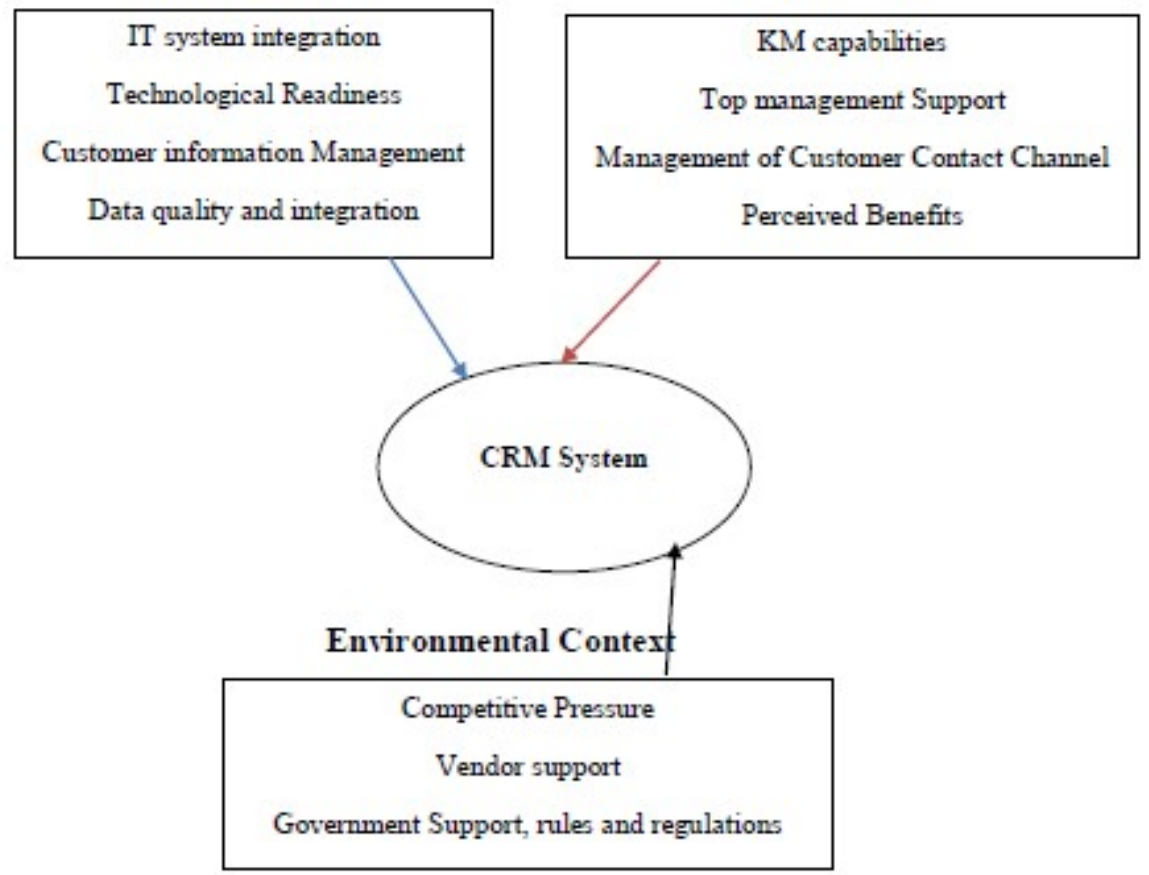

Figure1: Conceptual model for CRM system

3) Environmental Context - The environmental dimension contains of "the arena" in which an organization conducts its activity, competitors, suppliers, comprising its industry and relations with governmental agencies (Cruz-Jesus et al., 2019).

- Competitive pressure relates to the level of weight felt by their rivals, being perceived as a significant driver in the adoption of technology (Cruz-Jesus et al., 2019).

- Vendor Support for adopting new technology, organizations show their high concern regarding the vendor support (Alshawi, Missi, \& Irani, 2011). A vendor's quality of service can often be demonstrated during the purchasing process when evaluating software packages.

- Government support, rules and regulations denotes different types government policies, strategies to help the appropriation of new advances or development (Hasani, Bojei, \& Dehghantanha, 2017).

\section{Methodology}

In this stage, we selected some factors by reviewing selected papers about important factor of CRMS. We have selected those factors which might affect CRM software solution to a company.

We used the ANP, the Analytical Hierarchy Process (AHP)cannot work a huge of feedback, dependencies and interactions between lower and higher level criteria, alternatives and the ANP is the generalization of AHP. In other words, the ANP works more flexible by giving interdependent relationships and measurement among decision factor and alternatives (Saaty, 1980). After that, the fuzzy logic is applied with the ANP which is named fuzzy ANP. In comparison to other methods, fuzzy ANP is more suitable for weighting criteria. Another way, CRM system selection represents an issue in which there is limited of certain information and many factors regarding this analysis. Another way is that, some certain information is known, some information claims uncertainty and unknown which called is a grey area. Because of that is why we adopted another approach called Grey Relational Analysis Approach.

\subsection{Analytic Network Process}

Many decision problems cannot be solved by hierarchically e.g. AHP. Therefore, ANP was implemented. The structure of clusters and nodes make a network which looks more complex than AHP. Though it looks more complex, the pair wise comparison, dependency is just act like AHP. The dependency in hierarchically cannot specified all possible conditions. The significance of criteria and alternatives shows in hierarchy though the significance of alternatives themselves produces the importance of criteria. The feedback from the network enables us to determine that factor what we need to find out future desired. The interdependency among criteria 
and alternatives is utilizing properly from hierarchical network.

\subsection{The Fuzzy Logic}

The fuzzy set is describable by a function like membership function. The membership function also characterizes the elements within a certain interval, which is originally [0,1]. This interval is most widely used for expressing the degree. It is known as the unit interval. After that, the degree of membership function denotes the extent that an element belongs to set or not. If the value is 1 , it is completely agreeing with membership function. That means, the element is in the set. If the value is 0 , it is not belonging to set. The remaining value between 0 and 1 is representing the membership in fuzzy sets with a certain degree. A fuzzy set develops different parameter as degree of membership of elements. In our study, we have introduced triangular fuzzy numbers as TFN which 1 to 9 as parameter to capture the judgement. It also helps to capture the lucidity.

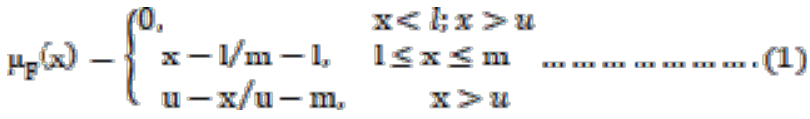

The TFN is structuring in a way that which improves the 1 to 9 conventional schema. To take the judgement of human perception in qualitative object, the TFN used the five points scale (Alshawi et al., 2011,9) for membership function. The TFN value is depicted in figure. With the help of TFN, the comparison of matrices constructs to classify the judgement. To illustrate the fuzzy extension of the method, linguistically terms are selected. Now the pairwise comparison matrix of TFNs combined into a matrix which called Fuzzy judgement matrix A (aij) is created as set below:

$$
A=\begin{array}{ccccc}
1 & a_{12} & \ldots \ldots \ldots & a_{1 n} \\
\vdots & 1 & \ldots & \cdots & \ldots \\
a_{n 1} & \cdots & 1 & \ldots & a_{n n}
\end{array}
$$

Here fuzzy eigenvalue, $\lambda$, is a fuzzy number result to:

$A x=\lambda x$

Where, $\lambda_{\max }$ is the largest eigenvalue of A. to directly estimate the consistency of pair-wise comparisons, consistency ratio (CR) is used. From a table of Random Consistency Index (RI), the CR is calculated by separating the $\mathrm{CI}$ by a value obtained:

Finally, we can evaluate the result by fitting the value in manipulated matrix and multiplying the interdependency factor. After that we can get the synthesizing result of all calculation as

$$
w_{\text {criteria }}=\sum A_{k j}^{d} A_{k j a}^{\mathbb{l}} S_{i k j a} p_{j i}
$$

where $A_{k j d}$ is relative significance of sub criteria regarding criteria. $\mathrm{A}_{\mathrm{kjal}}$ is the stabilized relative importance between sub-criteria. $\mathrm{P}_{\mathrm{ja}}$ is relative importance with respect to criteria. $\mathrm{S}_{\mathrm{ikja}}$ is relative importance between sub criteria and alternatives.

\subsection{Ranking Alternatives: GRA with Fuzzy ANP}

In GRA,there are 3 main phases. The first phase is data pre-processing; it is usually essential when the range in one data sequence is dissimilar from others or the sequence scatter range is too large. It transfers the original data sequence to a comparable sequence.

$$
X^{*}(k)=\frac{z_{i}^{0}(k)-\min Z_{1}^{0}(k)}{\max x_{i}^{0}(k)-\min X_{i}^{0}(k)}
$$

The second phase is to locate the grey relational coefficient.

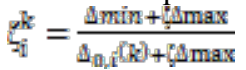

Then, grey relational grade (GRG) is computed by averaging the value of the grey relational coefficients.

$$
\gamma_{i=\frac{1}{n}} \sum_{k=1}^{n} \sum_{i}[k]-
$$

\subsection{Data collection}

The data was collected from 5 midlevel managers from Bangladesh. A close ended questionnaire was developed including criteria, sub-criteria and alternatives. The alternatives those we selected after pre-screening, we represented those as $\mathrm{S} 1, \mathrm{~S} 2, \mathrm{~S} 3, \mathrm{~S} 4 \& \mathrm{~S} 5$.

\section{Case Study and Discussion}

We have evaluated all pairwise comparison matrices and determined the eigenvalue for all comparisons. With a decent consistency ration, we have calculated the dependency among the criteria and goal. It shows the weight for every sub-criterion to criteria, criteria to goals and sub-criteria to goals. 
Table1: The weighted value from all matrix

\begin{tabular}{|c|c|c|c|c|c|c|c|c|c|}
\hline Criteria & Sub & $\mathrm{P}_{\mathrm{jz}}$ & $A^{\alpha_{j 2}}$ & $A_{2 j 2}$ & $\mathrm{~S}_{1 \mathrm{j} \mathrm{j}_{2}}$ & $\mathrm{~S}_{\mathrm{yja}}$ & $S_{3 j \mathrm{ja}}$ & $\mathrm{S}_{4 \mathrm{yja}}$ & $\mathrm{S}_{\mathrm{yj \textrm {a }}}$ \\
\hline \multirow[t]{4}{*}{ Technology } & ITS & .15 & .194 & 0.286 & .12 & .47 & .07 & .03 & .30 \\
\hline & $\mathrm{DQ}$ & .15 & .142 & 0.285 & .15 & .53 & .06 & .04 & .22 \\
\hline & TR & .15 & .614 & 0.284 & .15 & .23 & .07 & .06 & .48 \\
\hline & CIM & .15 & .050 & 0.287 & .15 & .50 & .06 & .04 & .24 \\
\hline \multirow[t]{4}{*}{ Organizational } & $\mathrm{KM}$ & .78 & .131 & 0.298 & .23 & .51 & .06 & .03 & .16 \\
\hline & TMS & .78 & .263 & 0.297 & .16 & .38 & .04 & .11 & .31 \\
\hline & $\mathrm{MCOC}$ & .78 & .037 & 0.296 & .11 & .32 & .02 & .02 & .56 \\
\hline & $\mathrm{PB}$ & .78 & .570 & 0.302 & .13 & .50 & .10 & .04 & .22 \\
\hline \multirow[t]{3}{*}{ Environmental } & VS & .07 & .311 & 0.310 & .07 & .43 & .17 & .04 & .28 \\
\hline & $\mathrm{CP}$ & .07 & .066 & 0.310 & .15 & .50 & .06 & .04 & .25 \\
\hline & GSR & .07 & .622 & 0.310 & .12 & .54 & .06 & .03 & .25 \\
\hline
\end{tabular}

Now, Table1 shows the main picture of ANP method. The pairwise comparison of all which described before and also the convergence result is displayed in Table1.Table2 shows the multiplication of all weighted value and the sum of all weighted value according to our 5 alternatives.

Figure 1: Graphical view of software rank

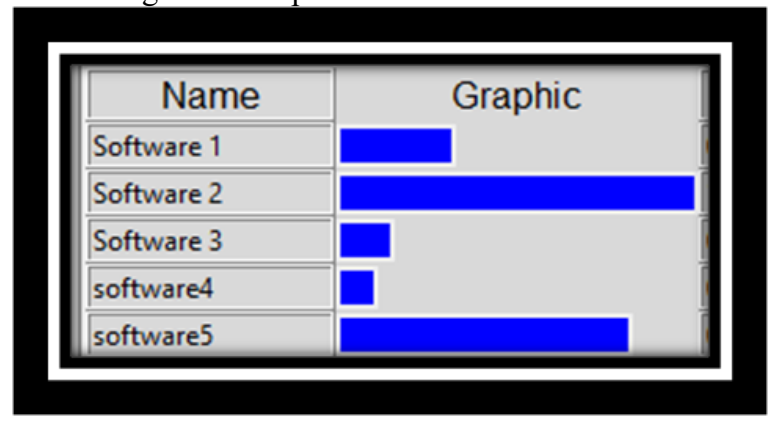

Table2: Multiplication of all weighted values and total sum

\begin{tabular}{|c|c|c|c|c|c|}
\hline & S1 & S2 & S3 & S4 & S5 \\
\hline ITS & .0010 & .004 & .0006 & .0002 & .002 \\
\hline DQ & .0009 & .003 & .0003 & .0002 & .001 \\
\hline TR & .004 & .006 & .002 & .002 & .013 \\
\hline CIM & .0003 & .001 & .0001 & .00009 & .0005 \\
\hline KM & .007 & .02 & .002 & .0009 & .005 \\
\hline TMS & .01 & .02 & .002 & .007 & .02 \\
\hline MCCC & .0009 & .002 & .0002 & .0002 & .005 \\
\hline PB & .02 & .07 & .01 & .005 & .03 \\
\hline VS & .0005 & .003 & .001 & .0003 & .002 \\
\hline CP & .0002 & .0007 & .00009 & .00006 & .0004 \\
\hline GSR & .002 & .007 & .0008 & .0004 & .003 \\
\hline Sum & 0.0468 & 0.1367 & 0.01909 & 0.01635 & 0.0819 \\
\hline
\end{tabular}

The GRG is representing the rank for the interdependency of all sub-criteria. After this we are going to multiply the effecting factors and GRG result to find out the best alternatives.

Table3: GRA result with ANP

\begin{tabular}{|c|c|c|}
\hline Alternatives & Value & Ranking \\
\hline S1 & 0.037232 & 3 \\
\hline S2 & 0.112779 & 1 \\
\hline S3 & 0.015724 & 4 \\
\hline S4 & 0.013249 & 5 \\
\hline S5 & 0.062834 & 2 \\
\hline
\end{tabular}

Below figures shows the comparison between our Result and software ANP result: 
Figure 2: Comparison between our result and super decision result

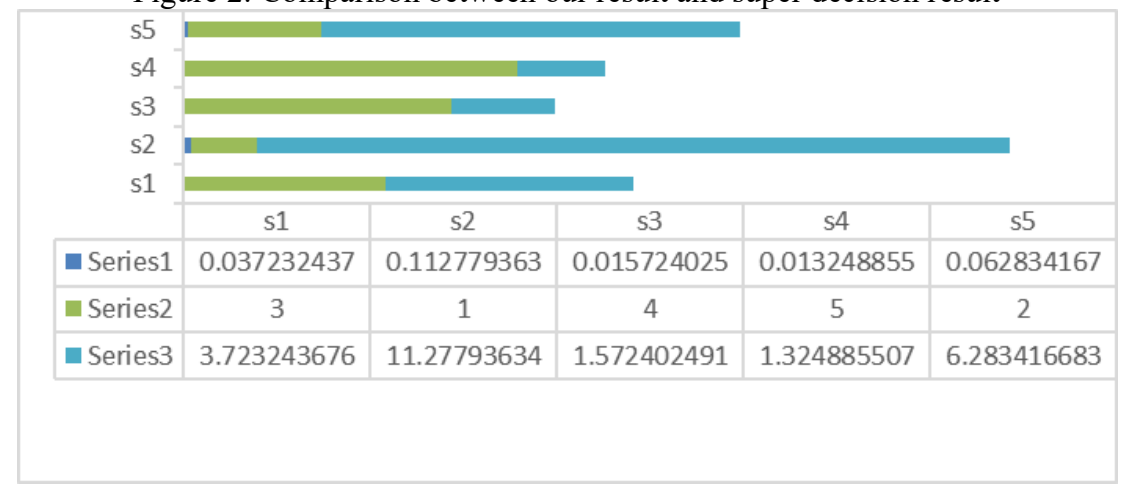

\section{Discussion}

In our research, to evaluate CRM system alternatives, the criteria and sub-criteria with quantitative value has been taken for our research approach. We applied the fuzzy ANP instead of primary ANP which was introduced by Saaty. The conventional ANP uses nine scale point. Because of uncertainty and vagueness of decisionmakers' preferences, the scale of pairwise comparison which used on primary ANP may not be precise and sufficient enough to measure the accurate judgments. That is why we used fuzzy ANP.

As well as, the GRA method is applied to deal with the grey information or unknown during the decisionmaking approach. The result of fuzzy ANP with GRA approach can use to find the distances more effectively from maxima and minima to referenced vector and high relational grade with right decision. It is noticeable that the inputs are examined in both GRA and Fuzzy ANP process. It also ensures that the preferences for desired outcome are in consistent level and robustness of the result.

The approach is a well-structured methodology that consists of GRA with fuzzy ANP advantage, and attains an efficient solution for CRM system selection problems. The more calculation and more time consuming is the disadvantage of this system. The software that calculates automatically the approach can easily solve these problems with more alternatives and criteria.

On the other way, the cooperation of the organization management from middle to upper is mandatory for this approach and the approach can be work more effectively with a cross validation team. When defining the criteria and alternatives the team must need support from external and internal resources. The cooperation of upper management is motivating the team and its member to confirm that the CRM system is implemented successfully.

\section{Conclusion and Recommendations}

The conceptual model in our research is all about the Criteria and sub-criteria. We have found out those criteria which makes our research in context of Bangladesh for a CRM system. We found out the factors which effect the CRM system like IT system Integration, Data Quality and Data integration, Technological Readiness and Customer Information Management Under Technological Context. According to Environmental context, these factors are KM capabilities, Top management Support, Management of Customer Contact Channel, Perceived Benefits and the Environmental context consists of Vendor Support, Government Dimensions, Competitive Pressure. After the findings of Criteria, we have ranked our alternatives in context of Bangladesh. The order that we have find out is $\mathrm{S} 2>\mathrm{S} 5>\mathrm{S} 1>\mathrm{S} 3>\mathrm{S} 4$ which shows the $\mathrm{S} 2$ is the optimal solution

In our research, we have faced with some problems which is our limitation. The CRM system is not so available in our country why the data is not so available. The result of this approach is dependent on the decision makers input. So, it is more obvious to bias the judgment for any particular system. That is why, it cannot be ruled out. Another problem is that Inconsistency may occur in the comparison which can provide wrong results. There are so many opportunities for expanding the approach. Its structural phase, uncertainty, and usefulness in decision making environment raises practical challenges in real world.The applicability of this approach quite complex. The another is, number of criteria and related sub-criteria can also affect the result of fuzzy ANP to determine the interdependency between them. The number of criteria and sub criteria will also increase the complexity. For future work, it will be more effective to divide more sub-factors into more factors. Knowledge based or an expert system may be developed to calculate such complex measurement more efficiently. There are so many decision making problems in the world. This approach can also work with them properly.

\section{References}


Alshawi, S., Missi, F., \& Irani, Z. (2011). Organisational, technical and data quality factors in CRM adoptionSMEs perspective. Industrial Marketing Management, 40(3), 376-383.

Cruz-Jesus, F., Pinheiro, A., \& Oliveira, T. J. C. i. I. (2019). Understanding CRM adoption stages: empirical analysis building on the TOE framework. 109, 1-13.

Day, G. S. J. J. o. t. a. o. m. s. (2000). Managing market relationships. 28(1), 24-30.

Francis Arthur Buttle, S. M. (2015). Customer Relationship Management: Concepts and Technologies. routledge. doi: $10.4324 / 9781351016551$

Hasani, T., Bojei, J., \& Dehghantanha, A. (2017). Investigating the antecedents to the adoption of SCRM technologies by start-up companies. Telematics and Informatics, 34(5), 655-675.

HOSSAIN, F. R. (2019). SAP Partners and Business Scenario in Bangladesh. Retrieved from https://brainstation-23.com/sap-partners-companies-bangladesh/

Khodakarami, F., Chan, Y. E. J. I., \& Management. (2014). Exploring the role of customer relationship management (CRM) systems in customer knowledge creation. 51(1), 27-42.

Oliveira, T., \& Martins, M. F. J. E. J. o. I. S. E. (2011). Literature review of information technology adoption models at firm level. 14(1), 110.

Petrik, A. (October 3, 2017). What are the advantages of CRM software? Retrieved from https://www.quora.com/What-are-the-advantages-of-CRM-software

Racherla, P., Hu, C. J. J. o. H., \& Marketing, L. (2008). eCRM system adoption by hospitality organizations: A technology-organization-environment (TOE) framework. 17(1-2), 30-58.

Reinartz, W., Krafft, M., \& Hoyer, W. D. J. J. o. m. r. (2004). The customer relationship management process: Its measurement and impact on performance. 41(3), 293-305.

Richards, K. A., \& Jones, E. J. I. m. m. (2008). Customer relationship management: Finding value drivers. 37(2), $120-130$

Saaty, T. (1980). The analytic hierarchy process (ahp) for decision making. Paper presented at the Kobe, Japan.

Zahedi, M., Cheshmberah, M., \& Tofighi, S. J. M. S. L. (2011). An empirical study to identify and rank CSFs in customer relationship management (CRM): A case study of oil products distribution. 1(4), 595-606. 